\section{ÁLCOOL E VIOLÊNCIA: TORCIDAS ORGANIZADAS DE FUTEBOL NO BRASIL}

\author{
ALCOHOL AND VIOLENCE: BRAZILIAN ORGANIZED FOOTBALL FANS
}

ALCOHOL Y VIOLENCIA: HINCHADAS DE FÚTBOL EN BRASIL

\author{
Thiago Brandão*, Mauricio Murad*, Rachel Belmont**, \\ Roberto Ferreira dos Santos*
}

\begin{abstract}
Palavras chave:
Violência.

Futebol.

Saúde pública.

Segurança pública

Resumo: A violência entre torcedores de futebol é um problema de segurança pública no Brasil. O propósito deste estudo é contribuir para o debate que relaciona o consumo de álcool e a violência entre torcedores de futebol. Trata-se de uma pesquisa de abordagem qualitativa-quantitativa, cujos dados foram obtidos por meio de análise documental, entrevistas semiestruturadas, observações e teste AUDIT. Dois grupos de dez torcedores homens, maiores de idade, participaram do estudo. Estatísticas de segurança apontam que ocorrências policiais diminuíram após a proibição da venda e consumo de álcool em estádios brasileiros. O álcool e outras drogas (ilícitas) são mais consumidos fora dos estádios por grupos de torcedores violentos. Segundo o protocolo AUDIT, $50 \%$ dos torcedores submetidos ao teste apresentaram consumo de alto risco e $10 \%$, provável dependência. Portanto, o consumo de álcool pode ser um importante agente desencadeador de violências no futebol e por isso merece atenção e políticas públicas adequadas.
\end{abstract}

Keywords:

Violence.

Soccer.

Public Health.

Safety.

Palabras clave:

Violencia.

Fútbol.

Salud Pública.

Seguridad.

Abstract: Violence among football fans is a public safety problem in Brazil. The purpose of this study is to contribute to the debate that relates alcohol consumption and that violence. A qualitative-quantitative research was conducted where data were obtained through documentary analysis, semi-structured interviews, observations, and the AUDIT test. Two groups of ten male fans over 18 years of age participated as volunteers. Public safety statistics indicate that police occurrences decreased after the ban on alcohol sales and consumption at Brazilian stadiums. Alcohol and other - illegal - drugs are consumed more often outside stadiums by violent fans. According to the AUDIT protocol, $50 \%$ of the fans presented highrisk consumption habits and $10 \%$ presented likely dependence. Therefore, alcohol consumption can be an important trigger of violence in football and therefore deserves attention and proper public policies.

Resumen: La violencia entre hinchadas de fútbol es un problema de seguridad pública en Brasil. El propósito de este estudio es contribuir con el debate que relaciona el consumo alcohólico y la violencia entre los hinchas de fútbol. Se trata de una investigación con enfoque cualitati-vo y cuantitativo, cuyos datos se obtuvieron mediante análisis documental, entrevistas se-miestructuradas, observaciones y la prueba AUDIT. Dos grupos de diez hinchas hombres, mayores de edad, participaron del estudio. Las estadísticas de seguridad muestran que los delitos se han reducido tras la prohibición de la venta y consumo de alcohol en estadios brasileños. El alcohol y otras drogas (ilícitas) son más consumidos fuera de los estadios por grupos de hinchas violentos. Según el protocolo AUDIT, un $50 \%$ de los hinchas sometidos a la prueba presentaron consumo alcohólico de alto riesgo y un $10 \%$ de ellos una probable dependencia. Por lo tanto, el consumo alcohólico puede ser un importante agente desenca-denante de violencia en el fútbol y, por ello, merece atención y políticas públicas adecua-das.
* Universidade Salgado de Oliveira. Niterói, RJ, Brasil.

E-mail: prof.thiagobrandao@gmail.com; m.mauriciomurad@gmail.com; rob.fersantos@oi.com.br

** Fundação Oswaldo Cruz. Rio de Janeiro, RJ, Brasil. E-mail: rachelsbelmont@gmail.com

Recebido em: 21-02-2019 Aprovado em: 04-07-2019 Publicado em: 31-01-2020 


\section{INTRODUÇÃO}

O hooliganismo ocorre em âmbito quase global, e no caso brasileiro a situação ganhou contornos dramáticos, entre 2009 e 2012, quando alcançamos primeiro lugar no ranking de mortes de torcedores, comprovadas pelo inquérito policial. Segundo Murad (2017), em 2013 foram 30 óbitos, índice altíssimo, consequência de conflitos entre gangues infiltradas nas torcidas de futebol. Ultrapassamos a Itália e a Argentina, países que estiveram a nossa frente por mais de uma década. O debate sobre a liberação do consumo de bebidas alcoólicas em estádios brasileiros, acirrado no biênio 2013/2014, Copa das Confederações e Copa do Mundo, trouxe à tona uma problemática de investigação complexa e multifacetada.

A violência praticada por torcedores de futebol é um antigo problema de segurança pública global (MURAD, 2017). O Brasil é o país com maior número de mortes comprovadas por confrontos entre grupos violentos, porém minoritários, de torcidas organizadas. Na soma dos seis anos mais agudos dessas conjunturas (2012 /2013/2014/2015/2016/2017), foram contabilizados 86 óbitos (MURAD, 2017). Todos relacionados a confrontos de torcidas, conforme os inquéritos da Polícia Civil (RIO DE JANEIRO, 2012). A violência no futebol brasileiro cresceu com o passar dos anos devido ao aprofundamento dos contextos sociais violentos no país, a impunidade e o descaso das autoridades. As práticas de violência no futebol foram crescendo e se espalhando à vista de todos, conflitos divulgados e combinados pelas redes sociais, e sob o silêncio do Estado brasileiro. No início, as brigas se resumiam a eventos isolados. Hoje, os processos de agressividade se ramificaram formando novas redes de brutalidade, eventos que as investigações policiais e acadêmicas coletam nos campos de pesquisa.

Outro fator de agravamento do quadro de ilicitudes no futebol é a comprovada conexão com o chamado crime organizado e o tráfico de drogas, comuns nas cidades brasileiras (MURAD, 2017), como indicado nos Relatórios dos Ministérios Públicos do Rio de Janeiro, São Paulo, Minas Gerais, Pernambuco e Ceará (ASSOCIAÇÃO NACIONAL DOS MEMBROS DO MINISTÉRIO PÚBLICO, 2018). Há também evidência de outras dimensões da violência entre grupos minoritários de torcedores agressivos ligadas à "busca da excitação" (ELIAS,1995), pois tentam até mesmo fixar regras, limites às práticas violentas, como o não uso de armas, atos de covardia e a prevalência de "briga só na mão".

Levantamento realizado por Murad (2017) sinaliza para uma sofisticação da violência, aumento do sadismo e mostra que certas mortes foram planejadas em detalhes. O autor sugere ainda ser possível comparar essa nova modalidade de crimes, com requintes de impiedade, a atos classificados como terroristas, no sentido de agir de forma calculada, cruel e aguda, contra coletivos muitas vezes indefesos, gerando o sentimento de pânico e de insegurança em imensas massas humanas. As causas desse cenário de violência no futebol são complexas, multifatoriais, estruturais e conjunturais. Um dos elementos dessas causas, que tem sido estudado no Brasil e em outros países, é a bebida alcoólica, por potencializar o grau de agressividade e violência (HABERSTICK; SMOLEN; HEWITT, 2006) em diversos setores da vida social, no trânsito (vide a Lei Seca), no ambiente familiar (HABERSTICK; SMOLEN; HEWITT, 2006; MASCARENHAS et al., 2009; ROEBUCK; MATTSON; RILEY, 1999; SILVA et al., 2012) e no futebol. 
A primeira vez que o poder público tomou medidas para combater o consumo do álcool em estádios brasileiros foi em 1995, em São Paulo, depois de uma tragédia que resultou na morte de um torcedor de 16 anos e deixou mais de 100 feridos. Em consequência, proibiu-se a venda e o consumo de bebida alcoólica nos estádios (REIS, 2006; SÃO PAULO, 1996). Rio Grande do Sul, Rio de Janeiro e Pernambuco adotaram medidas semelhantes. No nível nacional, a Confederação Brasileira de Futebol (CBF) proibiu bebidas alcoólicas em seus campeonatos, por meio da Resolução da Presidência (RDP) 01/2008, acordo celebrado com o Ministério Público Federal (CONSELHO NACIONAL DE PROCURADORES GERAIS, 2013).

Embora a lei 10.671 (BRASIL, 2003), "Estatuto do Torcedor", seja divulgada como a responsável pela proibição da bebida alcoólica nos estádios, este é no mínimo dúbio ao referir-se a 'bebidas'. O art. 13-A, parágrafo II do Capítulo IV, que trata da segurança do torcedor, estabelece que este deve "não portar objetos, bebidas ou substâncias proibidas ou suscetíveis de gerar ou possibilitar a prática de atos de violência". Desta forma, o documento não faz referência direta a bebida alcoólica, e sim a bebidas em geral. Água também é bebida e a conclusão do parágrafo Il pode ser interpretada - e isso já ocorreu na prática -, como um complemento tão somente de "substâncias". O governo brasileiro, ainda assim e com a intenção de se resguardar - tendo em vista a dubiedade reconhecida da matéria - quando da elaboração da lei 12.663 (BRASIL, 2012), "Lei Geral da Copa", entendeu ser necessária a retirada do artigo 13-A, para legitimar a liberação da venda e do consumo de álcool nos estádios, durante a Copa das Confederações, 2013, e a Copa do Mundo, 2014. Segundo o Art. 68 desta lei "Aplicam-se a essas competições, no que couberem, as disposições da Lei no 10.671, de 15 de maio de 2003" e, em seu inc. $1^{\circ}$ "Excetua-se da aplicação supletiva constante do caput deste artigo o disposto nos arts. 13-A a 17 [...]". A alteração foi consequência do lobby das grandes cervejarias, patrocinadores milionários da FIFA e de seus megaeventos.

A liberação trouxe à tona novamente o debate sobre consumo de álcool e violência praticada por torcedores de futebol. Não há um consenso em relação à matéria, nos estudos e trabalhos dos especialistas. O tema é polêmico e vários estudos chegam a conclusões diversas. Importante pesquisa encontra-se em Nepomuceno et al. (2017). É necessário ressaltar que, apesar de utilizarem uma metodologia distinta da nossa, os referidos autores sublinham questões mais ou menos próximas às apontadas neste estudo. Ademais, eles concluíram que a venda e o consumo de álcool exercem pouca influência sobre o comportamento de torcedores violentos.

Dunning (2011 apud Reis, 2012) acredita que o consumo de bebida alcoólica não tem "nenhuma relação" com o hooliganismo e argumenta que nem todos os hooligans bebem e nem todos os que bebem brigam. Reis $(2006,2012)$ considera que resumir toda a violência no futebol ao consumo de bebida alcoólica é um reducionismo, que não tem fiabilidade empírica, porém admite que o hooliganismo deve ser abordado por uma visão multifatorial, com variadas causas convergentes e a bebida alcoólica representa, indubitavelmente, um desses fatores.

Murad (2017), por outro viés de investigação, concluiu uma gama de resultados, em distintas séries históricas estatísticas, que convergem com Reis $(2006,2012)$. O autor explica que o relaxamento no controle do álcool e outras drogas acabou por acentuar uma relação de permissividade, que somada ao ambiente hostil que cerca o universo do hooliganismo, em determinadas circunstâncias e determinados segmentos 
de torcedores, formou uma conexão explosiva no âmbito das práticas de violência no futebol. Além disso, o autor ainda afirma que as investigações nas áreas médica e social vêm apontando que o alcoolismo é um dos fatores que, associado a outras razões, ajudam a explicar a violência no trânsito, na família e no futebol, não como causa única e/ou principal, mas como causa associada e potencializadora. O etanol reduz a autocrítica e o autocontrole conforme estudos nas áreas médica - clínica e psiquiátrica - e social - pedagógica, jurídica, psicológica. Isto faz do alcoolismo um problema de segurança pública, além de uma questão de saúde pública.

Para Toledo (1996), que ao relativizar a dimensão da violência entre as torcidas e suas causas geradoras, o álcool inclusive, defende que "[...] o torcedor é o trabalhador, o estudante, a dona de casa, o malandro, o marginal, o policial, o dirigente político. A condição de torcedor é apenas mais uma entre tantos outros papéis sociais desempenhados pelos indivíduos na sociedade" (p.12). Portanto, uma análise que tenha o seu enfoque somente nas práticas de violência corre sério risco de não ser satisfatória por gerar uma visão fragmentada. Neste caso, se observaria a agressão, que em tese seria a última etapa de uma cadeia sucessiva de eventos. Embora a dimensão da violência seja importante e cada vez mais atual na cultura do torcedor, esta não é a principal característica das torcidas de futebol, que são entes associativos, de inclusão cultural e pertencimento existencial.

Como desdobramento da "Lei Geral da Copa", bebidas alcoólicas nos estádios e em áreas adjacentes foram liberadas entre o fim de 2015 e o início de 2016, em vários estados brasileiros. Uma das justificativas genéricas foi a de que não havia estudos que comprovassem a relação entre o consumo de álcool e violência entre torcedores. Esse postulado metodológico e político é discutível, uma vez que há diversas pesquisas acadêmicas e estudos operacionais mostrando essa relação de causalidade (MURAD, 2017; REIS, 2006, 2012; ASSOCIAÇÃO BRASILEIRA DE PSIQUIATRIA, 2016; ASSOCIAÇÃO BRASILEIRA DO ESTUDO DO ÁLCOOL E OUTRAS DROGAS, 2018; ASSOCIAÇÃO NACIONAL DOS MEMBROS DO MINISTÉRIO PÚBLICO, 2018). Reconhecendo que a violência no futebol tem várias motivações, fenômeno multifatorial, o propósito deste estudo é contribuir para o debate que relaciona o consumo de álcool e violência entre torcedores de futebol.

\section{CAMINHOS METODOLÓGICOS}

Estapesquisaqualitativa-quantitativa (THOMAS;NELSON;SILVERMAN, 2012) foi realizada com torcedores do Rio de Janeiro, entre 2013 e 2014, com atualizações até 2017. Para a coleta de dados foram realizadas: análise documental, entrevistas semiestruturadas, observações assistemáticas e o Teste AUDIT (ALCOHOL USE DISORDERS IDENTIFICATION TEST). Foram desenvolvidos estudos separados, mas não independentes, complementares, integrados e convergentes. A pesquisa foi submetida ao Comitê de Ética da Universidade e seus participantes aceitaram participar do estudo voluntariamente sob garantia do sigilo.

\subsection{ANÁLISE DOCUMENTAL}

Pela análise documental foram obtidas estatísticas e informações, em documentos oficiais de três estados do país: São Paulo, Pernambuco e Minas Gerais. Os registros (números, tipos de ocorrências, relações com o público presente nos 
estádios etc.) foram comparados em dois momentos específicos: um anterior e outro posterior à liberação do álcool. Esses três estados foram os eleitos por apresentarem as investigações mais sistemáticas e consistentes. Os dados em seus documentos são de instituições relacionadas com a problemática da violência no futebol: Polícia Militar, Corpo de Bombeiros, Polícia Civil, Ministério Público e Defesa Civil. As informações e estatísticas são do site do Conselho Nacional de Procuradores-Gerais.

\subsection{ENTREVISTAS}

As entrevistas semiestruturadas (BAUER; GASKELL, 2011) foram realizadas com dez membros homens de uma torcida organizada do Rio de Janeiro. Os participantes tinham idade mínima de 18 anos, eram associados ao clube e tinham participação ativa média de dez anos. A seleção dos participantes foi feita a partir de uma pré-amostra de trinta torcedores (cerca de 30\% dos 105 membros desse segmento da organizada, chamado de "família"), todos envolvidos com práticas de violência e consumo de álcool, indicação de alguns diretores da organizada, por vezes, coniventes com eles. As entrevistas foram agendadas por telefone, feitas pessoalmente em uma praça, local escolhido pelos depoentes e próximo à residência de um deles. As questões indagavam sobre estrutura e funcionamento da torcida, contextos de ingresso e formação de novos membros, organização da ida aos jogos, consumo de álcool e práticas de violência. A fim de dar maior fiabilidade empírica aos dados coletados, as entrevistas foram gravadas e, após as transcrições, um novo encontro foi marcado para conferência de informações (ALVES-MAZZOTTI; GEWANDSZNAJDER, 2002).

\subsection{OBSERVAÇÃO}

As observações assistemáticas (ALVES-MAZZOTTI; GEWANDSZNAJDER, 2002) foram fundamentais para o contato real com os processos e agentes sociais do campo da pesquisa. Operacionalizadas em cinco dias de jogos do Campeonato Brasileiro A de 2013 e mais cinco de 2014, no entorno (raio de 500 m) e no interior do estádio do Maracanã. A observação se deu em três momentos distintos e complementares: antes, durante e após as partidas. Foram observados eventos relacionados aos torcedores e o consumo de bebida alcoólica. Os pesquisadores chegaram a todos os jogos com três horas de antecedência do início da partida. Isso foi essencial para perceber, acompanhar e aquilatar como se inicia o processo de interação dos torcedores com a bebida alcoólica no entorno do estádio, nos bares, restaurantes, carrocinhas e ambulantes.

\subsection{ALCOHOL USE DISORDERS IDENTIFICATION TEST (AUDIT)}

O teste AUDIT é um instrumento utilizado pela Organização Mundial de Saúde (OMS), desenvolvido por Babor et al. (1992) e adaptado à realidade brasileira por Méndez (1999). Tem a função de mensurar o nível do consumo de bebida alcoólica em determinado agrupamento e sua relação com os distúrbios ali ocorridos. O AUDIT é composto por dez questões relativas ao período dos últimos 12 meses, sendo que as três primeiras buscam identificar o volume e a regularidade do consumo de álcool. As três seguintes visam levantar os graus de dependência e as quatro últimas referem-se aos problemas de agressividade e violência relacionadas ao consumo de álcool. 
Outros dez membros da organizada, homens, com idades acima de 18 anos, indicados pelos mesmos diretores, aceitaram participar do teste, que foi aplicado diretamente, em uma reunião na sede da torcida.

\section{RESULTADO E DISCUSSÃO DA ANÁLISE DOCUMENTAL}

Como já dito, a CBF proibiu o álcool em estádios pela Resolução da Presidência 01/2008. Antes, alguns estados proibiram em momentos distintos e por iniciativa própria. São Paulo, Pernambuco e Minas Gerais foram os destaques em atos proibitivos, bem como em pesquisas, para comparar as práticas de violência, antes e depois da proibição.

Tabela 1 - Proibição de bebida alcoólica nos estádios de futebol de São Paulo

\begin{tabular}{lccc}
\hline \multicolumn{1}{c}{ Ano } & 1995 & 1996 & 1997 \\
\hline Quantidade de eventos & 261 & 227 & 362 \\
Quantidade de público & 1.587 .878 & 1.122 .852 & 2.105 .299 \\
Média de público & 5.969 & 4.946 & 5.816 \\
Efetivo escalado & 14.882 & 13.779 & 18.406 \\
Média de efetivo & 57 & 81 & 51 \\
Ocorrências atendidas & 1.260 & 420 & 641 \\
Média de ocorrência & 4,8 & 1,9 & 1,8 \\
Detidos & 1553 & 624 & 932 \\
Média de detidos & 5,9 & 2,7 & 2,6 \\
\hline
\end{tabular}

Fonte: Polícia Militar do Estado de São Paulo (CONSELHO NACIONAL DE PROCURADORES GERAIS, 2013)

Em São Paulo, a proibição vigorou em 1996 (CAPINUSSÚ, 1996; MURAD, 2017; ROEBUCK; MATTSON; RILEY, 1999), antes, portanto, do "Estatuto do Torcedor", em outra conjuntura política, econômica e social do Brasil. As ocorrências policiais caíram de 1260, em 1995, para 420, em 1996 (Tabela 1). No ano seguinte, houve uma retomada das ocorrências, devido a um afrouxamento das ações policiais e judiciais, reconhecido pelas autoridades.

O caso da região do Recife, estado de Pernambuco, que proibiu em 2007 (CONSELHO NACIONAL DE PROCURADORES GERAIS, 2013), é uma das destacadas referências e das mais duradouras, conforme pode ser visto no quadro a seguir.

Quadro 1 - Ocorrências violentas nos estádios de futebol no grande Recife

\begin{tabular}{|c|c|}
\hline Ano & Ocorrências \\
\hline 2004 & 825 \\
\hline 2005 & 1643 \\
\hline 2006 & 736 \\
\hline 2007 & 468 \\
\hline 2008 & 132 \\
\hline 2009 & 229 \\
\hline 2010 & 112 \\
\hline
\end{tabular}

Fonte: Ministério público do Estado de Pernambuco (CONSELHO NACIONAL DE PROCURADORES GERAIS, 2013) 
Nesse estado, a partir de maio de 2006, tem início o funcionamento do Juizado Especial Cível e Criminal do Torcedor (JETEP), que fiscalizou após 2017 a proibição da venda e do consumo de bebidas alcoólicas. Fazem parte desse órgão as Polícias Civil e Militar, Ministério e Defensoria Pública, Secretaria de Defesa Social e Ordem dos Advogados do Brasil (OAB). O JETEP tem por finalidade resguardar direitos e deveres assegurados pelo "Estatuto do Torcedor" (BRASIL, 2003), destaque para a segurança, e pode operar desde a área civil, com problemas de funcionamento no estádio, até a área criminal, com casos de lesão corporal leve, ameaça à vida e homicídios. O Quadro 1 apresenta uma queda nos índices violentos, a partir de 2007, ano da proibição e, por consequência, de uma ação mais coordenada da polícia e da justiça.

Em Minas Gerais, os dados foram disponibilizados pelo comando do Corpo de Bombeiros (CONSELHO NACIONAL DE PROCURADORES GERAIS, 2013) e são do estádio do Mineirão (Quadro 2). As médias de 39 e dez atendimentos por jogo foram registradas em 2006 e 2007, respectivamente, representando redução de quase $75 \%$.

Quadro 2 - Número de ocorrências registradas por jogo no Mineirão em 2006 e 2007

\begin{tabular}{|c|c|c|c|}
\hline \multicolumn{2}{|c|}{ Antes da proibição - 2006 } & \multicolumn{2}{c|}{ Após a proibição - 2007 } \\
\hline Jogos & Ocorrências & Jogos & Ocorrências \\
\hline Cruzeiro X Atlético & 64 & Atlético X Vila Nova & 15 \\
\hline Atlético X Avaí & 48 & Cruzeiro X Guarani & 31 \\
\hline Atlético X São Raimundo & 32 & Cruzeiro X Atlético & 8 \\
\hline Atlético X América RN & 36 & Cruzeiro X Ituiutaba & 89 \\
\hline Cruzeiro X Corinthians & 39 & Cruzeiro X Tupi & 0 \\
\hline Cruzeiro X Goiás & 28 & Atlético X Democrata & 0 \\
\hline Cruzeiro X Santa Cruz & 25 & Atlético X América & 0 \\
\hline Atlético X Ceará & 33 & Cruzeiro X Democrata & 1 \\
\hline Cruzeiro X Santos & 37 & Atlético X América RJ & 0 \\
\hline Atlético X Paulista & 48 & Atlético X Democrata GV & 0 \\
\hline \multicolumn{2}{c|}{} & & de Bombericos Ménas Geras. \\
\hline
\end{tabular}

Fonte: Comando Geral do Corpo de Bombeiros de Minas Gerais. (CONSELHO NACIONAL DE PROCURADORES GERAIS, 2013)

Ainda em Minas Gerais, o Gráfico 1 apresenta valores comparativos, disponibilizados pelas Polícias Civil e Militar. Segundo o $1^{\circ}$ Departamento de Polícia de Belo Horizonte, registrou-se em 2007 um público total de 167.150 pessoas no estádio, ao passo que 2006 somou 114.728, o que demonstra o aumento da presença de público, após a proibição da bebida alcoólica. Além disso, destaca-se a queda das práticas de violência. Em 2006 houve uma ocorrência para cada 1550 torcedores e, em 2007, uma ocorrência para cada 2880 torcedores. Esses números mostram uma redução de mais de $45 \%$ nos índices de práticas violentas do Campeonato Mineiro, comparando o período de 2006, onde a venda e o consumo de bebida alcoólica eram liberados, com 2007, quando passou a ser proibida (Gráfico 1). 
Gráfico 1- Número de ocorrências no Campeonato Mineiro nos anos de 2006 e 2007

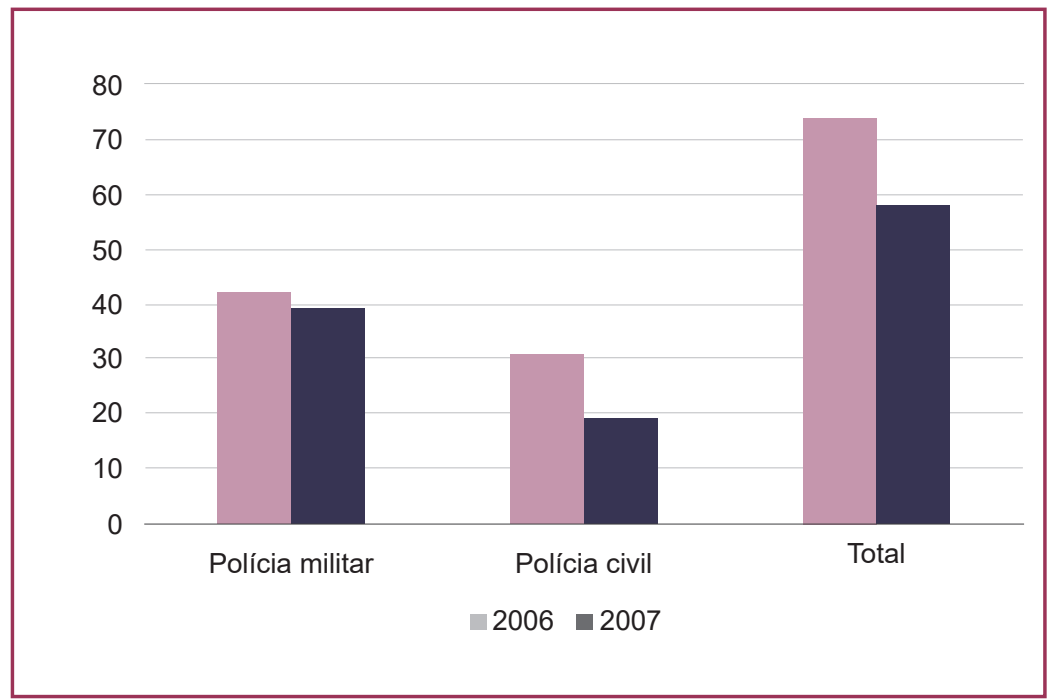

Fonte: $1^{\circ}$ Departamento de Polícia de Belo Horizonte.

(CONSELHO NACIONAL DE PROCURADORES GERAIS, 2013)

Diante dos resultados, é possível verificar que houve redução nos índices de distintas práticas de violência nos três estados, comparado os períodos antes e após a proibição de bebidas alcoólicas. Segundo o comandante geral do Corpo de Bombeiros de Minas Gerais: "Não foram só os números de atendimento que diminuíram, mas também a gravidade dos quadros apresentados de depredação, agressividade e violência" (CONSELHO NACIONAL DE PROCURADORES GERAIS, 2013).

\section{DISCUSSÃO DAS ENTREVISTAS SEMIESTRUTURADAS}

Os entrevistados demonstraram maior vínculo e afeto aos símbolos da torcida organizada do que ao próprio clube, o que sinaliza uma relação "fatiada" com o universo daquele time, de sua história e tradição. A fala do torcedor a seguir expressa essa ideia: "Os braços (pessoal da pancadaria) amam a torcida mais do que o clube. A nossa bandeira é a da torcida... [...]. Quando arrancamos à força a camisa do inimigo, a da torcida vale mais do que a do time". Um envolvimento assim "partidarizado", que valoriza só parte da torcida (facção agressiva) ao invés da globalidade, significa uma ideologia não universal com a cultura clubística. Isto pode potencializar o "espírito de corpo", ou seja, um sentimento autocentrado que admite a exclusão do "outro", visto como "inimigo", sobretudo torcedores de times rivais, e até torcedores do mesmo time, mas de outros grupos. Dessa forma, a violência poderá vir a seguir como se depreende do fragmento de diálogo entre o pesquisador $(P)$ e um dos torcedores $(\mathrm{T})$ :

P: Como é a relação de vocês com a bebida alcoólica?

T: A galera bebe legal, igual a água (risos).

P: Que tipo de bebida alcoólica é a mais consumida?

T: Cerveja e cachaça. Vodca só quando tem uns Playboy.

P: Você acha que o consumo de bebida alcoólica aumenta a chance de um cara desses arranjar um tumulto, sair no tapa com alguém?

T: Tenho certeza, eles bebem pra isso, não só bebem como se drogam.

P: Para criar coragem? 
T: Com certeza, o cara chega lá de cara limpa e manso (risos), quando termina a concentração já virou um leão.

$\mathrm{P}$ : Como é a relação dos torcedores com a bebida alcoólica?

T: O pessoal bebe bem, mas a grande maioria desses torcedores mistura com droga mesmo: maconha, cocaína e crack.

$P$ : Onde e quando a galera bebe?

T: A gente se encontra antes de ir para o jogo em alguns pontos, às vezes até em bares mesmo aí começa.

$P$ : E a relação com o clube como é?

T: O clube que se f., não tô nem aí, minha relação é com a torcida, vou lá para defender a torcida.

No entendimento da maioria (repetido por quase 80\%) desses torcedores violentos, os confrontos com os adversários são demonstrações de "força e poder necessários para manter o respeito e a estrutura da torcida viva e funcionando satisfatoriamente". Note bem: "da torcida".

Relataram também (67\%) que o consumo de drogas lícitas e ilícitas destacaram o álcool, a maconha e a cocaína - é muito frequente e funciona como combustível, como encorajamento, para essas "necessárias" ações aguerridas. Afirmaram ser "necessário", já que "os outros de outras torcidas também fazem uso dessas drogas". Quando questionados se determinados indivíduos que tenham bebido muito podem cometer atos de violência, foram categóricos e unânimes ao dizer que sim. Demonstraram conhecimento empírico, dando exemplos de "certos carinhas" que se tornam mais violentos, após períodos na concentração da torcida, onde a bebida alcoólica é intensa, além de "abrir caminho" para "drogas mais pesadas". Segundo eles, "não é só a bebida, que faz o confronto, mas ela ajuda, não há dúvida".

Essas facções violentas são minoritárias e não representam as torcidas organizadas como um todo. Estima-se que tais grupos correspondam a 5\% dos integrantes das torcidas mais aguerridas, cerca de 70 agremiações das mais de 700 no Brasil (MURAD, 2017).

\section{RESULTADO E DISCUSSÃO DAS OBSERVAÇÕES}

Com a observação in loco, foi possível ter uma visão holística a respeito da violência praticada por grupos de torcedores de futebol e sua relação com o álcool. Essa imersão na experiência confere maior confiabilidade empírica à investigação.

Embora a venda de bebidas alcoólicas no entorno do estádio Maracanã seja proibida por lei (RIO DE JANEIRO, 1998), no período de duas horas antes e duas depois das partidas, foi possível constatar o não cumprimento do previsto na legislação, tanto por parte dos ambulantes, quanto de bares e restaurantes (JÚNIOR; SEDA, 2013). A bebida alcoólica foi comercializada livremente, sem fiscalização ou repressão nos termos das leis em vigor. A presença ostensiva da força policial no mesmo cenário do cometimento do ilícito, à vista de todos, permite supor conivência e corrupção. E o efeito disso é o sentimento de impunidade, estimulante de novos delitos e transgressões, muito particularmente entre os grupos violentos, que afirmaram: "com a polícia e a justiça, dá em nada".

Os mecanismos de controle estadual (Polícia Militar), e municipal (Guarda Municipal e Secretaria de Ordem Pública - SEOP), se mostraram tolerantes, até 
coniventes, com a comercialização da bebida alcoólica. A exceção se deu em parte pela SEOP, de forma pontual, num dos dias da observação: realizava-se uma operação fiscal e nesta apreenderam grande quantidade de cerveja de alguns ambulantes. No entanto, a SEOP não agiu com o mesmo rigor na punição a bares e restaurantes, permitindo a venda no horário proibido em lei.

Em relação aos torcedores organizados, mais ainda aos agressivos, ficou claro, como foi exposto nas entrevistas, que o consumo de bebida alcoólica ocorre muitas vezes de maneira excessiva. Esses segmentos demonstraram "excitação" (ELIAS, 1995) e animosidade maiores, após período nos bares próximos do complexo esportivo, onde foi possível se observar agressões verbais e físicas. Depois de muito álcool, no longo tempo de "concentração" nos bares, antes de entrarem no estádio, esses grupos com frequência saíam correndo, derrubando mesas e cadeiras, não raro, sem pagar a conta na totalidade. Havia policiamento no lugar, porém pouco ou nada foi feito.

\section{RESULTADO E DISCUSSÃO DO TESTE AUDIT}

O testeAUDIT (BABOR et al., 1992; MÉNDEZ, 1999) situou assim os torcedores organizados: Abstêmios: 30\%; Consumo de baixo risco: 10\%; Uso nocivo ou consumo de alto risco: 50\%; Provável dependência: 10\%. O teste confirmou a observação e as entrevistas: de fato, há uma tendência ao consumo abusivo do álcool no contexto das torcidas organizadas (RIO DE JANEIRO, 1998), nomeadamente entre as facções mais agressivas, aquelas envolvidas, reincidentemente, nas ocorrências policiais e registradas nos arquivos, tanto da Polícia Militar quanto da Polícia Civil. Em verdade, esses grupos são gangues infiltradas, minorias agressivas e arruaceiras, com ligações já constatadas pela investigação policial com o crime organizado e o tráfico de drogas.

Constatou-se que $30 \%$ dos indivíduos são abstêmios e $10 \%$ se enquadraram na faixa de baixo risco, porém o índice de $50 \%$ de consumo de alto risco é preocupante, conforme o protocolo do AUDIT. E se considerarmos o índice de $10 \%$ de provável dependência e o ambiente que cerca as torcidas organizadas, tantas vezes "militarizado" culturalmente, de intolerâncias, de exclusões, de comportamentos machistas, ambiente de multidão e paixão, que tudo acentuam, o álcool, apesar de não ser o fator, é um dos fatores, porque "turbina a agressividade". Os casos de maior gravidade se situaram na faixa de 10\% de "provável dependência alcoólica", até porque é nessa faixa que, às vezes, o consumo de "drogas pesadas" se faz sentir de modo mais evidente. Os números obtidos representam um alerta para as autoridades, uma vez que o alcoolismo é um grave problema de saúde e segurança coletivas, alerta que pode e deve provocar políticas públicas concernentes.

\section{CONSIDERAÇÕES FINAIS}

A violência praticada por torcedores de futebol não tem um único agente causador. É um fenômeno multifatorial. Dessa forma, não há uma solução única capaz de resolver toda essa problemática. Identificamos que a bebida alcoólica pode ser um desses agentes desencadeadores de conflitos violentos, em diferentes setores da vida social, inclusive no futebol. O etanol, assim comprovam as pesquisas 
médicas, reduz a autocrítica e o autocontrole, podendo facilitar a transgressão e a violência, especialmente em determinados grupos sociais e determinados "campos" (BOURDIEU, 2000) de atuação e manifestação cultural.

Após a proibição da venda e consumo de bebidas alcoólicas em estádios, houve significativas quedas nas ocorrências policiais dos três estados analisados. Pernambuco apresentou queda de $63 \%$, São Paulo, de 57\% e Minas Gerais, $45 \%$. Nesse período, também foi identificado o aumento do público nos estádios. No entanto, além da proibição do consumo do álcool, outras variáveis, não apresentadas neste estudo, como o desempenho esportivo dos clubes e a qualidade do espetáculo futebolístico, podem ter contribuído para isso.

Membros de torcidas entrevistados afirmaram que o consumo de álcool e outras drogas é comum no ambiente das organizadas, particularmente nos grupos violentos. Alegaram que os torcedores, muitas vezes, utilizam essas substâncias com o objetivo de "criar coragem" para os confrontos.

Quanto aos torcedores organizados submetidos ao teste AUDIT, 50\% se enquadraram na faixa de consumo de alto risco e $10 \%$ na faixa de provável dependência. Números que comprovam uma tendência ao abuso de bebida alcoólica entre os torcedores organizados.

O decreto $\mathrm{n}^{\circ} 30.417$, de 22 de janeiro de 2009 , que proibiu a venda de bebidas alcoólicas no entorno do Maracanã, duas horas antes e duas depois dos jogos, quando implementado foi cumprido. O motivo da proibição, segundo o decreto, é que havia recorrentes violências causadas por indivíduos alcoolizados, que perturbavam a ordem pública. Apesar disso, ao longo de uma década, o decreto nem sempre foi respeitado e sua fiscalização foi insuficiente, por parte dos governos, da justiça e das polícias, sobretudo na Copa (2013/2014) e nos Jogos Olímpicos em 2016.

Diferentemente do que é exposto em boa parte do discurso midiático, o "Estatuto do Torcedor" não proíbe a venda e o consumo de bebidas alcoólicas em estádios. O art. 13-A, II, única parte da lei que se refere à bebida, não especifica se trata de bebidas alcoólicas ou não. Esse artigo é no mínimo dúbio. A questão do alcoolismo entre torcedores, além de ser um grave problema de segurança pública, é um problema de saúde coletiva e por isso deveria provocar políticas públicas, por parte das autoridades brasileiras, o que não vem ocorrendo.

Embora os resultados indiquem redução das ocorrências violentas com a proibição do consumo de álcool, e este é um sinal relevante, não é aconselhável estabelecer uma relação de causalidade direta e definitiva entre as variáveis. Novas pesquisas, incluindo as de desenho experimental, devem ser realizadas, a fim de complementar e interpretar mais profundamente as realidades distintas das diversificadas regiões brasileiras e, assim, contribuir para a construção de políticas públicas de segurança e saúde coletiva. 


\section{REFERÊNCIAS}

ALVES-MAZZOTTI, Alda J.; GEWANDSZNAJDER, Fernando. O Método nas ciências naturais e sociais. 2. ed. São Paulo: Pioneira, 2002.

ASSOCIAÇÃO BRASILEIRA DE PSIQUIATRIA. Relatório Anual. 2016. Disponível em: https://www.abp.org.brl. Acesso em 16 fev. 2019.

ASSOCIAÇÃO BRASILEIRA DO ESTUDO DO ÁLCOOL E OUTRAS DROGAS.

Relatório Semestral - Julho/Dezembro de 2018. 2018. Disponível em: https://www. abead.com. Acesso em: 15 jan. 2019.

ASSOCIAÇÃO NACIONAL DOS MEMBROS DO MINISTÉRIO PÚBLICO. Relatório Trienal dos MPs Estaduais 2016/2017/2018. 2018. Disponível em: https://www.br/ conamp.org/pt/. Acesso em: 28 jan. 2019.

BABOR, Thomas F.; FUENTE, Juan R.; SAUNDERS, John; GRANT, Marcus. AUDIT The alcohol use disorders identification test: guidelines for use in primary health care. Genebra: World Health Organization/PAHO, 1992. Disponível em: http://citeseerx. ist.psu.edu/viewdoc/download?doi=10.1.1.505.4146\&rep=rep1\&type=pdf. Acesso em 27 jun. 2018.

BAUER, Martin W.; GASKELL, George. Pesquisa qualitativa com texto, imagem e som: um manual prático. 11. ed. Petrópolis: Vozes, 2011.

BOURDIEU, Pierre. A dimensão simbólica da dominação. Rio de Janeiro: Graal, 2000.

BRASIL. Lei $n^{\circ}$. 10.671, de 15 de maio de 2003. Dispõe sobre o Estatuto de Defesa do Torcedor e dá outras providências. Diário Oficial da União. Brasília. DF, 16 maio 2003. Seção 1, p. 1. Disponível em: http://www2.camara.leg.br/legin/fed/lei/2003/lei10671-15-maio-2003-496694-publicacaooriginal-1-pl.html. Acesso em: 05 jan. 2017.

BRASIL. Lei $n^{\circ}$. 12.663, de 05 de junho de 2012. Dispõe sobre as medidas relativas à Copa das Confederações FIFA 2013, à Copa do Mundo FIFA 2014 e à Jornada Mundial da Juventude - 2013, que serão realizadas no Brasil; altera as Leis $n^{\circ} 6.815$, de 19 de agosto de 1980, e 10.671, de 15 de maio de 2003; e estabelece concessão de prêmio e de auxílio especial mensal aos jogadores das seleções campeãs do mundo em 1958, 1962 e 1970. Diário Oficial da União. Brasília, DF, 06 jun. 2012. Seção 1, p. 3. Disponível em: http://www2.camara.leg.br/legin/fed/lei/2012/lei-12663-5junho-2012-613164-publicacaooriginal-136362-pl.html. Acesso em: 05 jan. 2017.

CAPINUSSÚ, José Maurício. Comunicação e transgressão no esporte. Rio de Janeiro: IBRASA, 1996.

CONSELHO NACIONAL DE PROCURADORES GERAIS (CNPG). Prevenção e combate à violência nos estádios. 2013. Disponível em: http://www.cnpg.org.br/index. php/prevencaoe-combate-a-violencia-nos-estadios/3333-documentos. Acesso em: 27 mar. 2018.

ELIAS, Norbert. Em busca da excitação. Lisboa: Difel, 1995.

HABERSTICK, Brett C.; SMOLEN, Andrew; HEWITT, John K. Family-based association test of the 5HTTLPR and aggressive behavior in a general population sample of children. Biological Psychiatry, v. 59, n. 9, p.836-843, 2006. Disponível em: https://doi. org/10.1016/j.biopsych.2005.10.008. Acesso em: 30 jun. 2018. 
JÚNIOR, Janir; SEDA, Vicente. Comércio ilegal de bebidas: ampolas de vodca são vendidas no Maracanã. Globo Esporte/Futebol. 2013. Disponível em: http:// globoesporte.globo.com/futebol/noticia/2013/11/comercio-ilegal-de-bebidas-ampolas-devodca-sao-vendidas-dentro-do-maracana.html. Acesso em: 27 mar. 2018.

MASCARENHAS, Márcio Dênis M.; MALTA, Deborah C.; SILVA, Marta Maria A.; CARVALHO, Cynthia G.; MONTEIRO, Rosane A.; MORAES NETO, Otaliba L. Consumo de álcool entre vítimas de acidentes e violências atendidas em serviços de emergência no Brasil, 2006 e 2007. Ciência \& Saúde Coletiva, v. 14, n. 5, p.17891796, 2009. Disponível em: http://dx.doi.org/10.1590/S1413-81232009000500020. Acesso em: 28 jan. 2018.

MÉNDEZ, Eduardo B. Uma versão Brasileira do AUDIT (Alcohol Use Disorders identification Test). Pelotas, 1999. 128f. Dissertação (Mestrado em Epistemologia) Universidade Federal de Pelotas, Rio Grande do Sul, 1999.

MURAD, Mauricio. A Violência no futebol: novas pesquisas, novas ideias, novas propostas. São Paulo: Saraiva/Selo Benvirá, 2017.

NEPOMUCENO, Thyago Celso. C.; MOURA, Jadielson Alves de; SILVA, Lúcio Câmara e; COSTA, Ana Paula Cabral Seixas. Alcohol and violent behavior among football spectators: An empirical assessment of Brazilian's criminalization. International Journal of Low and Justice, v. 51, p. 34-44, 2017. Disponível em: https://doi. org/10.1016/j.jijlcj.2017.05.001. Acesso em: 17 jun. 2019.

REIS, Heloisa Helena B. Futebol e violência. São Paulo: Fapesp, 2006.

REIS, Heloisa Helena B. Lei geral da Copa, álcool e o processo de criação da legislação sobre violência. Movimento, v. 18, n. 1, p. 69-99, 2012. Disponível em: https://doi.org/10.22456/1982-8918.26484. Acesso em: 2 mar. 2018.

RIO DE JANEIRO (Estado). Polícia Civil. Operação Fair Play prende oito torcedores do Flamengo. Na ação foram apreendidas armas, drogas, automóveis e dinheiro falso. 2012. Disponível em: http://www.policiacivil.ri.gov.br/exibir.asp?id=15819. Acesso em: 27 mar. 2014.

RIO DE JANEIRO. Lei $n^{\circ} 2.991$, de 23 de junho de 1998. Proíbe a venda de bebidas alcoólicas destiladas nos estádios de futebol e em suas proximidades, em todo o estado do rio de janeiro, e dá outras providências. Diário Oficial do Estado do Rio de Janeiro. RJ, 24 jun. 1998, Seção 1, p.8. Disponível em: https://gov-rij.jusbrasil.com.br/ legislacao/143960/lei-2991-98. Acesso em: 8 fev. 2018.

ROEBUCK, Tresa M.; MATTSON, Sarah N.; RILEY, Edward R. Behavioral and psychosocial profiles of alcohol-exposed children. Alcoholism: Clinical and Experimental Research, v. 23, n. 6 p.1070-1076, 1999. Disponível em: https://doi. org/10.1111/j.1530-0277.1999.tb04227.x. Acesso em: 2 out. 2018.

SÃO PAULO. Lei n. 9.470, de 27 de dezembro de 1996. Dispõe sobre a manutenção de toda a lotação com lugares numerados nos estádios de futebol, ginásio de esporte e estabelecimentos congêneres. Diário Oficial do Estado de São Paulo. SP, 28 dez. 1996, Seção Executivo I, p. 2-3. Disponível em: https://www.al.sp.gov.br/repositorio/ legislacao/lei/1996/lei-9470-27.12.1996.html. Acesso em: 22 set. 2018.

SILVA, Jairo V.; CASTRO, Viviane; LARANJEIRA, Ronaldo; FIGLIE Neliana B. High mortality, violence and crime in alcohol dependents: 5 years after seeking treatment in a Brazilian underprivileged suburban community. Revista Brasileira de Psiquiatria, v. 34, n. 2, p. 135-142, 2012. Disponível em: http://dx.doi.org/10.1590/S151644462012000200004. Acesso em: 20 out. 2018. 
THOMAS, Jerry R.; NELSON, Jack K; SILVERMAN, Stephen J. Métodos de pesquisa em atividade física. 6. ed. Porto Alegre: Artmed, 2012.

TOLEDO, Luiz H. Torcidas organizadas de futebol. Campinas: Autores Associados/ ANPOCS, 1996. 